\title{
Supply Chain Coordination Considering Stochastic Demand and Raw Material Quality Defects*
}

\author{
Li Yongfei \\ ${ }^{1}$ School of Economic and Management, Xi'an University of Posts and \\ Telecommunications, Xi'an, China \\ ${ }^{2}$ Shaanxi Philosophy and Social Science Research base - Information Industry \\ Development Research Center, Xi'an, China \\ Lyfking2000@163.com
}

\begin{abstract}
This paper solves the coordination strategies of a supplier and a manufacturer separately under the condition of decentralized, centralized and revenue sharing supply chain based on Steinberg non-cooperative game theory. The research presumes: 1)The manufacturer completely inspects materials of supplier; 2) The manufacturer repairs the unqualified products resulting from supplier's raw material quality defects; 3) the single manufacturer faces a random demand under single period newsboy model. We find out that marginal effect will be enlarged when the manufacturer repairs the unqualified productions. When supply chain is coordinated, EOQ, total profit and total risk-sharing of centralized supply chain are larger than that of non-coordination or decentralized supply chain. The integrated model of revenue sharing supply chain can achieve the performance of centralized supply chain. The establishment of this integration will not be affected by changes in wholesale price of suppliers. Our research can provide some theoretical basis for supply chain to reduce internal and external risk loss costs.
\end{abstract}

Keywords: Supply Chain Coordination; Raw Material Quality Defect; Stochastic Demand; Revenue Sharing Contract

\section{Introduction}

Along with the unceasing enhancement of customer consumption level, the customer requires increasingly high product quality, which has become one of the core factors in supply chain competition. It is a pity, however, that almost all kinds of products have certain proportion of defective works in the realistic environment. The proportion has a critical influence on the quality of final products [1-3]. When the quality defect surpasses a specific level, the operation, the coordination and the revenue of the whole supply chain will suffer negative impact. Therefore, in this process, it is great significance to consider how quality defect and its return strategies incurred by this will affect the coordination of supply chain [3-5].

Meanwhile, with the trend of globalization and customization, customer demand is getting so random that it has already become the basic environmental factor which supply chain decision-makers need to encounter. As a result, demand uncertainty leads to the

\footnotetext{
*Foundation Item: National Social Science Fund of China (15BGL014); The scientific research project of Shaanxi Provincial Department of transportation (15-01R); Special Research Project in Shaanxi Province Department of Education(15JK1663); National Natural Science Foundation of China (71173172); Social Science Fund Project of Shaanxi province (13SC014);.XUPT university New Star Group Fund (XY201506); China Society of Logistics Research Fund (2015CSLKT3-165)

Li Yongfei, Dr, lecturer, School of economics and management, Xi'an University of post and telecommunications. Research directions: logistics and supply chain management, transportation planning and management, quality management. Tel: +008613572884108; E-mail:lyfking2000@163.com
} 
inferior in-coordination and imbalance risk sharing of supply chain. Therefore, the problem on stochastic demand is not only a difficult problem that decision-makers need to effectively tackle with but also a core question to supply chain researchers, attracting many researchers' attention [6-8].

In addition, most supply chains are practically decentralized, whose objectives are different and conflicted based on independent benefits of each party [9]. Confronted with the problems of quality defect of raw materials or stochastic demand, each party in supply chain attempts to optimize its own benefit and minimize the risk, which induces the phenomenon of "double marginalization" to impair the whole profit of the supply chain. Hence, it is imperative to construct a reasonable coordination mechanism to restrain each party [9-10]. In particular, when the stochastic demand and the quality defect coexist and display their functions, their synergism role needs to be fully discussed among supply chain researchers [7-8].

\section{Literature Review}

Most scholars study the situation when only one single firm in supply chains developsquality defects. Salameh and Jaber (2000) studied a single manufacturer whose products had quality defects [11]. Based on the objective of profit maximization, they showed the optimal results via Economic Order Quantity (EOQ) model when the manufacturer inspected all goods to find out defective ones, and then sold them at a lower price. However, they assumed the demand was fixed and did not consider the situation of stochastic demand. Later, Eroglu and Ozdemir (2007), Maddah and Jaber (2008) modified the model of Salameh and Jaber (2000) and developed the study in stochastic demand situation[1]-5]. Their research demonstrated the optimal order quantity was increasing along with the inspective rate and the variability of the defective items. Besides, Ferguson et al. (2006) and Hwang et al. (2006) considered the situation where the buyer returned defective goods to suppliers or manufacturers when product quality defects occurred, but they did not focus on stochastic demand [12-13].

In fact, stochastic demand is a core problem which arouses researchers' attention. The demand uncertainty leads to the inefficiency and waste in supply chain, and further undermines the coordination of each party and the balance of risk sharing. Mostard et al. (2005) followed the principles of reselling and adjourned sale to establish a derivative stochastic Newsboy model to tackle with the practical problem when some distributors requested to return goods after receiving the order [14]. Eynan and Kropp (2007) proposed a method to integrate stochastic demand into the EOQ problems with Taylor series expansion, and further constructed an EOQ model containing stochastic demand, variable inventory cost and safety stock [15]. He and Zhang (2008) studied the coordination and risk-sharing problem as to a two-stage supply chain including one supplier and one retailer under the conditions of uncertain production demand[16]. They found that under certain circumstances, stochastic production could promote the performance of supply chain and protected it from the side effect of double marginalization. Further, Kelle et al. (2009) introduced factors affecting safety stock from the uncertainty of product quality to inspect its effects on supply chain coordination[19]. Wang and Xiao (2009), Chick (2008) discussed supply chain coordination under return policies of proportion buy-back and discount buy-back, respectively [20-21]. Their findings indicate that return policy could coordinate supply chain by making wholesale price accord with marginal cost - plus pricing method and allowing retailer to return surplus order at wholesale price. However, their consideration had not turned to the influence of supply chain coordination from the quality defect of raw materials.

Some scholars studied EOQ problems under synergism of the stochastic demand and quality defect. Su et al. (2011) considered that under the condition of stochastic demand and quality defect of raw materials, manufacturers adopted $100 \%$ inspection and no 
inspection on the items, and sold those defective items with cheap price and repair condition, respectively [6]. They found out that low-price selling had less influences on EOQ than repair, but it had larger marginal effect. However, they had only considered the influence on EOQ from stochastic demand and quality defects of raw materials, but the influence on supply chain coordination remained scarce.

Besides, some scholars studied the coordination problem under the synergism of stochastic demand and quality defect of raw materials. Su and Li (2011), Li et al. (2011) utilized Stackelberg non-cooperation model to study the coordination and risk-sharing of the supply chain with the occurrence of quality fault and return policy [6-7]. They considered a supply chain where a supplier provided one single product to a retailer in one period, under the situation where there still existed quality fault in the product after selfinspection of the supplier and random inspection of the retailer. They suggested that both parties should coordinate to determine defective items process strategies which are either repair or low-price selling and to determine their optimal profit, order quantity and risksharing according to the severity of quality defect.

Above all, it is imperative to consider the coordination mechanism under stochastic demand and quality defects of raw materials in order to ensure items quality and meet customers' stochastic demand. With this mechanism, we can restrict each party in the supply chain to address double marginalization problem, thereby enabling the decentralized supply chain to achieve the performance of centralized one. Therefore, this paper constructs the coordination mechanism of decentralized, centralized and revenue sharing supply chain respectively with Steinberg non-cooperation game theory under the conditions of stochastic demand and quality defect of raw materials.

This paper makes several contributions as follows. First, we consider the effect paths, functions and results of the joint influence of stochastic demand and quality defect of raw materials based on supply chain coordination. Second, we construct a coordination mechanism to better share the risk and profit when the product of manufacturer has implied quality defect of raw materials, which avoids the double marginalization effect. Third, with this mechanism based on quality defect of raw materials, the decentralized supply chain can perform as well as centralized one which reduces the risk of total supply chain. This paper is organized as follows: In section 2, we review the related literature researches. In section 3, we introduce our basic model. In section 4, we construct EOQ and coordination models between one supplier and one manufacturer, in terms of decentralized, centralized and revenue sharing supply chain. In section 5, we analyze our research results. Finally, Section 6 summarizes the conclusions and provides some suggestions for future researches.

\section{Model Descriptions}

We consider a supply chain consisting of one manufacturer $M$ and one supplier $S$. We consider the total profit of the supply chain from the perspective of the difference between revenue and cost, which means the profit increases with this difference value. Besides, we assume the manufacturer and the supplier are both independent and risk neutral. Items are independent too. And we focus on one single period in disregard of the influence of subsequent periods. Also, we assume the demand follow a normal distribution. All stocks which have already ordered or produced can meet customers' needs without awaiting distribution. Besides, we assume the manufacturer orders quantity $Q$ from the supplier according to his forecast of uncertain demand at the beginning of each period, and then produce quantity $Q$ final items. When one batch of raw materials arrives, the manufacturer adopts complete inspection. Based on the assumption that all inspection results are of adequate dependability, all defective goods inspected have to be repaired, which transforms into internal losses instead of external losses, such as the cost from after sale service, compensation, consumer complaint, etc. In this manner, there are four kinds 
of cost involved in the paper, namely procurement cost for raw materials, manufactory cost, inventory cost and quality cost. Among these, inventory cost consists of shortage cost and surplus cost. Shortage cost refers to the cost caused by out-of-stock, including emergency procurement, loss on work stoppage and so forth. And surplus cost represents stockholding cost. Quality cost comprises inspection cost and internal losses. Inspection cost refers to the quality test of raw materials purchased from suppliers, while internal losses include scrap cost. Here, we assume the stockholding fee is linear proportional to the stock.

Assuming that $x$ is the customer stochastic demand variable of the manufacturer, and G follows a normal distribution, we can get $G(x)=P(X \leq x)$ as the demand cumulative distribution function and $g(x)=\frac{d}{d x} G(x)$ as the demand probability density function ${ }^{\text {[21- }}$ ${ }^{22]}$. Besides, let $u$ denote the demand mean, $\sigma$ denote the demand standard deviation, $c_{0}$ denote the excess cost per unit after demand is produced, $c_{s}$ denote the shortage cost per unit, $c_{i}$ denote the inspection cost per unit, $c_{r}$ denote the internal loss per unit of defective product, $c_{d}$ denote the external loss per unit, $\bar{p}$ denote the expected probability of defective product.

We assume the situation where the supplier $S$ sells the raw materials to the manufacturer $M$ at the wholesale price $w$, and then the manufacturer $M$ sells the final items to the customers at the price $P$. If the manufacturer $M$ determines the optimal order quantity according to his benefits, the order quantity will not be optimal for total supply chain due to the effect of double marginalization. At this moment, the contract of sharing revenue and risk might address the problem. With the contract restriction, the supplier will sell the raw materials to the manufacturer at lower-price $w_{\phi}$ which equals to his marginal cost. And the manufacturer retains the expected part of revenue $M\left(Q, w_{\phi}\right)=\left(P-c_{i}-c_{m}-w_{\phi}\right) Q$, namely $\phi M\left(Q, w_{\phi}\right)$, where $\phi \in[0,1]$. The $(1-\phi) M\left(Q, w_{\phi}\right)$ will refund to the supplier. If the price $P$ is immune to changes of demands, it will stay fixed in the short run and only be dependent on the market. Also, the profit of each other will be no less than that without the contract, and the supply chain will be poised in a coordinated state.

\section{Model Constructions}

\subsection{Decentralized Supply Chain Condition}

According to the model description, when the manufacturer inspects $100 \%$ items and repairs the defect goods, the revenue functions of the manufacturer, the supplier and total decentralized supply chain are as follows:

The manufacturer's revenue function is:

$\prod_{m}^{{ }^{\top}{ }^{\prime}}=P Q-c_{i} Q-c_{m} Q-w Q-S^{\prime}-O$

Where $c_{i} Q, c_{m} Q, w Q, S^{\prime}=c_{o} \int_{0}^{Q}(Q-x) g(x) d x, \quad O^{\prime}=c_{s} \int_{Q}^{\infty}(x-Q) g(x) d x$ denotes inspection cost, item cost, raw materials wholesale cost, surplus cost and out-of-stock loss cost, respectively 
We can get $\frac{d^{2} \prod_{M}^{T^{\prime}}}{d Q^{2}} \leq 0$, which indicates that the manufacturer's revenue function is convex and thus there exists maximum. Let the first derivative equal to zero, we can get below:

$$
G\left(Q^{*}\right)=\frac{P-c_{i}-c_{m}-\omega+c_{s}}{c_{o}+c_{s}}
$$

Then we can get the optimal expected profit of the manufacturer, the supplier and the

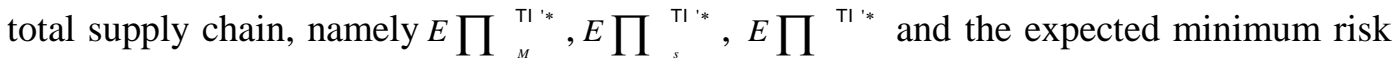
losses of the manufacturer, the supplier, total decentralized supply chain $\operatorname{ETC}_{M}\left(Q^{* *}\right)$, $E T C_{S}\left(Q^{\prime *}\right), \operatorname{ETC}\left(Q^{\prime *}\right)$, respectively.

\subsection{Supply Chain Coordination with Restriction of the Contract of Revenue Sharing}

The construction of the contract of sharing revenue can effectively mitigate conflicts between each party in the decentralized supply chain by increasing the profit sharing. It can further avoid the profit losses in a whole caused by individual profit maximization of each party. Besides, this contract can impede the occurrence of double marginalization and bullwhip effect, and thus enable the performance of decentralized supply chain to achieve the performance of centralized one and to reduce the risk that each party burdens.

The revenue functions of manufacturer, supplier and supply chain are as follows, respectively.

$$
\begin{aligned}
& \prod_{{ }^{\top}}^{\mathrm{T}^{\prime}}=\phi\left\{P Q-c_{i} Q-c_{m} Q-w_{\phi} Q-c_{r} Q \bar{p}-S^{\prime}-O^{\prime}\right\} \\
& \prod_{s^{\top}}^{\mathrm{T}^{\prime}}=(1-\phi)\left\{P Q-c_{i} Q-c_{m} Q-w_{\phi} Q-c_{r} Q \bar{p}-S^{\prime}-O^{\prime}\right\}+w_{\phi} Q-c Q \\
& \prod^{\mathrm{T}^{\prime}}=P Q-c Q-c_{i} Q-c_{m} Q-c_{r} Q \bar{p}-S^{\prime}-O^{\prime}
\end{aligned}
$$

We can get $\frac{d^{2} \prod_{m}^{{ }^{\prime}}}{d Q^{2}} \leq 0$. This shows that the manufacturer's revenue function is convex function, which indicates the existence of maximum value. Assume the first derivative equal to zero to get:

$G\left(Q^{* * *}\right)=\frac{P-c_{i}-c_{m}-w_{\phi}-c_{r} \bar{p}+c_{s}}{c_{o}+c_{s}}$

Likewise, the supplier's EOQ is:

$$
G\left(Q^{\prime \prime s}\right)=\frac{(1-\phi)\left(P-c_{i}-c_{m}-c_{r}-c_{s}\right)+\phi w_{\phi}-c}{(1-\phi)\left(c_{o}+c_{s}\right)}
$$

According to equations (6) and (7), with the restriction of the contract, the wholesale price is:

$$
w_{\phi}^{* * *}=c
$$

The EOQ model with the coordination between supplier and manufacturer: 
$G\left(Q^{\prime * *}\right)=\frac{P-c_{i}-c_{m}-c-c_{r} \bar{p}+c_{s}}{c_{o}+c_{s}}$

Hence, with the contract and the condition of coordination, $\mathrm{t}$ the supplier and the total

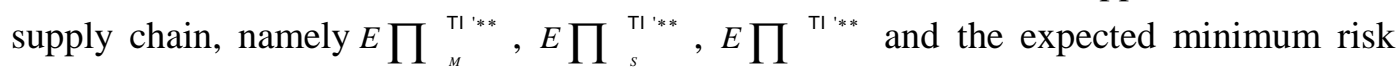
losses of the manufacturer, the supplier, total decentralized supply chain $E T C_{M}\left(Q^{* * *}\right)$, $\operatorname{ETC}_{S}\left(Q^{\prime * *}\right), \operatorname{ETC}\left(Q^{* * *}\right)$, respectively.

\subsection{Centralized Supply Chain Condition}

The centralized supply chain coordination takes the manufacturer and the suppler as a whole, thereby achieving the maximization of total revenue.

The expected revenue function of total supply chain is:

$E \prod^{\mathrm{T}^{\prime}}=P Q-c Q-c_{i} Q-c_{m} Q-c_{r} Q \bar{p}-S^{\prime}-O^{\prime}$

Likewise, we can get EOQ when the centralized supply chain achieved the total profit maximization:

$G\left(Q^{\prime * * *}\right)=\frac{P-c-c_{i}-c_{m}-c_{r} \bar{p}+c_{s}}{c_{o}+c_{s}}$

Then, the expected revenue of centralized supply chain is:

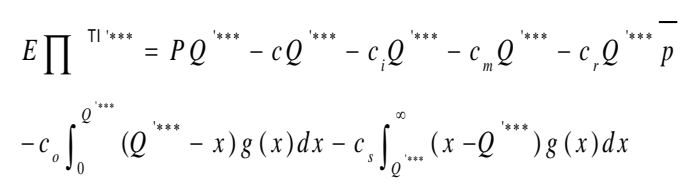

And the minimum expected risk loss of centralized supply chain is:

$$
\begin{aligned}
& \operatorname{ETC}\left(Q^{1 * * * *}\right)=c Q^{4 * * *}+c_{i} Q^{i * * *}+c_{m} Q^{i * * *}+c_{r} Q^{i * * *} \frac{-}{p} \\
& +c_{o} \int_{0}^{Q^{\prime * * *}}\left(Q^{\prime * * * *}-x\right) g(x) d x+c_{s} \int_{Q^{\prime \cdots *}}^{\infty}\left(x-Q^{* * * * *}\right) g(x) d x
\end{aligned}
$$

\section{Numerical Analysis}

Assuming in certain supply chain, the market demand follows a normal distribution $N\left(1,2^{2}\right)$, we fix $P=15, \bar{p}=0.001, c_{r}=1.2, c_{m}=1.5, c=3, c_{0}=2.3$, $c_{\mathrm{s}}=2.7, c_{i}=0.8, w=4, \phi=0.75$. And it can be calculated $w_{\phi}^{* *}=3$. Then EOQ, revenue and risk-loss sharing when the supply chain is decentralized, centralized and with the contract restriction to sharing revenue and risk are displayed respectively in Table 1, 2 and Table 3. 
Table 1. EOQ of the Supply Chain when Decentralized, Centralized and with the Contract Restriction of Sharing Revenue

\begin{tabular}{ccc}
\hline Supply chain types & EOQ Model & EOQ \\
\hline Decentralized supply chain & $G\left(Q^{* \prime}\right)=2.28$ & $Q^{\prime \prime}=2.98$ \\
Revenue sharing & $G\left(Q^{\prime * *}\right)=2.47$ & $Q^{* * *}=2.99$ \\
Centralized supply chain & $G\left(Q^{\prime * * *}\right)=2.47$ & $Q^{\prime * * *}=2.99$ \\
\hline
\end{tabular}

Table 2. The Expected Revenue of the Supply Chain when Decentralized, Centralized and with the Contract Restriction of Revenue Sharing

\begin{tabular}{cccc}
\hline & \multicolumn{3}{c}{ Expected revenue } \\
\cline { 2 - 4 } & Decentralized supply & Revenue & Centralized supply \\
chain & sharing & chain \\
Supplier & 2.98 & 6.65 & - \\
Manufacturer & 23.54 & 19.96 & - \\
supply chain & 26.52 & 26.61 & 26.61 \\
\hline \multirow{3}{*}{ Table 3. The Expected Risk Sharing of the Supply Chain when } \\
Decentralized, Centralized and with the Contract Restriction of Revenue \\
\multicolumn{3}{c}{ Sharing } \\
\hline \multicolumn{4}{c}{ Expected risk } \\
Supplier & Decentralized supply & Revenue & Centralized supply \\
& chain & sharing & chain \\
Manufacturer & 8.94 & 4.56 & - \\
supply chain & 21.15 & 13.68 & - \\
& 30.10 & 18.24 & 18.24 \\
\hline
\end{tabular}

From the Table 1, 2 and Table 3, decentralized supply chain optimal profit is less than the expected profit under revenue sharing contract coordination, and also less than the centralized supply chain expected profit but the risk is the opposite. But the risk when decentralized supply chain optimal profit is gotten is larger than the risks when the expected profit is gotten under revenue sharing contract coordination and the centralized supply chain expected profit is gotten.

It is apparent that under the contract of revenue sharing, the supplier's revenue has a substantial growth but the manufacturer's has slight decrease. Nevertheless, the risk confronted by each party drops precipitously. Besides, EOQ, revenue and risk-loss for total supply chain are equal to each counterpart in centralized condition and all outnumber them in decentralized ones. Therefore, this revenue sharing mechanism can help decentralized supply chain to achieve the performance of centralized one and reduce its risk.

\section{Conclusions}

The tendency of globalization and customization renders customer demands more uncertain and unpredictable. As customers turn to high requirement of product quality, more emphasis on quality has been placed by researchers and practitioners. The competition among supply chains has been comprehensive and multifaceted, not only for 
cost and price but also for quality, internal coordination and risk-sharing. Good quality enables each party in the supply chain to maintain his reputation, reduce risk losses and promote customer satisfaction and core competence. Hence, it is of critical importance to meet customers' needs and to consider the supply chain coordination and risk-sharing with quality defective of raw materials.

This paper constructs coordination strategy and risk-sharing mechanism for decentralized, centralized and revenue sharing supply chain with Steinberg noncooperation game theory. We consider this problem in the conditions when stochastic demands and quality defects of raw materials occur and when the manufacturer adopts complete inspection and repairs defective goods. It shows that the marginal effect increases unceasingly when we repair the defective items. It also finds out that when the demand follows a normal distribution, the EOQ will decrease linearly with defective goods, whereas the EOQ will increase linearly with the standard deviation when order quantity outweighs demand average. Besides, it indicates that the EOQ, total profit and total risk of centralized supply chain are higher than those of decentralized one. However, with the contract of sharing revenue, the decentralized supply chain can be as well as the centralized one performs, immune to the changes of supplier's wholesale price. The study lays a great foundation for the research on reducing internal and external risk losses in supply chains.

However, we acquiesce in the dependability of the inspection to ascertain the defective items, and do not consider the possibility of inspection failure, which can be studied in future research. Besides, we assume that the manufacture adopts complete inspection every time, which probably is not the case in practice. Therefore, we can study the supply chain coordination under quality defect of raw materials with respect to sampling inspection in the future.

\section{Acknowledgments}

Foundation Item: National Social Science Fund of China (15BGL014); The scientific research project of Shaanxi Provincial Department of transportation (15-01R); Special Research Project in Shaanxi Province Department of Education(15JK1663); National Natural Science Foundation of China (71173172); Social Science Fund Project of Shaanxi province (13SC014);.XUPT university New Star Group Fund (XY201506); China Society of Logistics Research Fund (2015CSLKT3-165).

\section{References}

[1] B. Maddah and M. Y. Jaber, "Economic order quantity for products with imperfect quality: Revisited", [J]. International Journal of Production Economics, vol. 112, no. 2, (2008), pp. 808-815.

[2] M. Y. Jaber, M. Bonney and I. Moualek, "An economic order quantity model for an imperfect production process with entropy cost", International Journal of Production Economics, no. 118, (2009), pp. 26-33.

[3] M. Y. Jaber, S. K. Goyal and M. Imran, "Economic production quantity model for items with imperfect quality subject to learning effects", International Journal of Production Economics, vol. 115, (2008), pp. 143-150.

[4] H. M. Wee, J. Yu and M. C. Chen, "Optimal inventory model for items with imperfect quality and shortage backordering, Omega, vol. 35, (2007), pp. 7-11.

[5] A. Eroglu and G. Ozdemir, "An economic order quantity model with defective products and shortages", International Journal of Production Economics, vol. 106, no. 2, (2007), pp. 544-549.

[6] Q. Su and Y. F. Li, "Supply chain coordination and risk sharing with considering internal quality fault and return policy", Operations Research and Management, accepted, (in Chinese), (2011).

[7] Y. F. Li, Q. Su and Z. Ouyang, "Supply Chain Coordination and Risk Sharing with Considering Internal and External Quality Fault and Return Policy", IE\&EM,vol. 9, (2011), pp. 1539-1543.

[8] Q. Su, Y. F. Li and W. Z. Li, "EOQ of manufacturer based on stochastic demand and material quality defect", Industrial Engineering and Management, (in Chinese), vol. 16, no. 1, (2011), pp. 31-36.

[9] I. Giannoccaro and P. Pontrandolfo, "Supply chain coordination by revenue sharing contracts", International Journal of Production Economics, vol. 89, no. 2, (2004), pp. 131-139. 
[10] T. Liu, B. Y. Li and Y. D. Gong, "Supply chain coordination policy and measure under trade credit", Systems Engineering Theory \& Practice, (in Chinese), vol. 30, no.8, (2010), pp. 1345-1354.

[11] M. K. Salameh and M. Y. Jaber, "Economic production quantity model for products with imperfect quality", International Journal of Production Economics, vol. 64, no. 1-3, (2000), pp. 59-64.

[12] M. Ferguson, "Supply chain coordination for false failure returns", Journal of Manufacturing \& Service Operations Management, vol. 8, no. 4, (2006), pp. 376-393.

[13] I. Hwang, S. Radhakrishnan and L. Su, "Vendor certification and appraisal: implications for supplier quality", [J]. Management Science, vol. 52, no. 10, (2006), pp. 1472-1482.

[14] J. Mostard, R. D. Koster and R. Teunter, "The distribution free newsboy problem with resalable returns", [J]. International Journal of Production Economics, vol. 97, no. 3, (2005), pp. 329-342.

[15] A. Eynan and D. H. Kropp, "Effective and simple EOQ-like solutions for customer stochastic demand periodic review systems”, European Journal of Operational Research, vol. 180, no. 3, (2007), pp. 11351143.

[16] Y. J. He and J. Zhang, "Random yield risk sharing in a two-level supply chain", International Journal of Production Economics, vol. 112, (2008), pp. 769-781.

[17] S. Foster, "Towards an understanding of supply chain quality management", Journal of Operations Management, vol. 65, (2007), pp. 234-251.

[18] C. K. Huang, "An optimal policy for a single-vendor single-buyer integrated production-inventory problem with process unreliability consideration”, International Journal of Production Economics, vol. 91, (2004), pp. 91-98.

[19] P. Kelle, S. Transchel and S. Minner, "Buyer-supplier cooperation and negotiation support with stochastic yield consideration", International Journal of Production Economics, vol. 118, no.1, (2009), pp. 152-159.

[20] X. Y. Wang and Y. M. Xiao, "Research on supply chain coordination and risk sharing based on buy back policy", Journal of Management Science, 2009, 12 (3): 65-70. (in Chinese)

[21] S. E. Chick, H. Mamani and S. L. David, "Supply chain coordination and influenza vaccination", Operations Research, vol. 56, no. 6, (2008), pp. 1493-1506.

[22] H. Kaynak and J. Hartley, "A replication and extension of quality management into the supply chain", Journal of Operations Management, vol. 5, (2007), pp. 45-67.

[23] S. Foster, "Towards an understanding of supply chain quality management", Journal of Operations Management, vol. 65, (2007), pp. 234-251.

[24] Q. H. Lu and D. L. Zhu, "Research on equilibriums and coordination strategies of supply chains with quality and price competition”, Journal of Management Science, (in Chinese), vol. 12, no. 3,(2009), pp. 56-64.

\section{Authors}

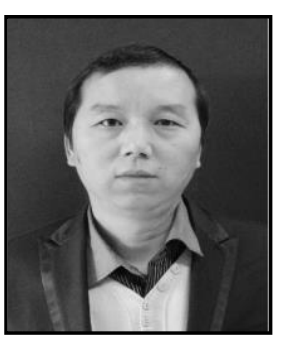

Li Yongfei, 1977-1, Linying, Henan, China. Tel:+008613572884108; Email:lyfking2000@163.com

Current position: Lecturer of Logistics E-commerce Department, School of Economics and Management, Xi'an University of Posts and Telecommunications and a worker of Shaanxi philosophy and social science research base-Information Industry Development Research Center. Degree: Phd, Scientific interest: Logistics and Supply Chain Management, Quality Management, Transportation Planning and Management. Publications <number or main>: Dr Li has published more than 40 papers. Experience: 1998.9-2002.6 Chang'an University Bachelor; 2002.7-2004.8 Shanxi traffic research institute Office of the Director, Project Chief Engineer. 2004.9-2007.7 Chang'an University Transportation Planning and Management Master; 2007.72009.7 Suzhou Taicang Transportation Bureau Transportation Planning Director; 2009.9-2013.12 Xi'an Jiao Tong University Management Science and Engineering Doctor; 2013.12 - Present Xi'an University of Posts and Telecommunications Lecturer. 
International Journal of $u-$ and e- Service, Science and Technology Vol.9, No. 5 (2016) 